\title{
Induction of fungal laccase production under solid state bioprocessing of new agroindustrial waste and its application on dye decolorization
}

\author{
Merve Akpinar ${ }^{1} \cdot$ Raziye Ozturk Urek ${ }^{2}$
}

Received: 7 November 2016/Accepted: 7 February 2017/Published online: 30 May 2017

(C) Springer-Verlag Berlin Heidelberg 2017

\begin{abstract}
Lignocellulosic wastes are generally produced in huge amounts worldwide. Peach waste of these obtained from fruit juice industry was utilized as the substrate for laccase production by Pleurotus eryngii under solid state bioprocessing (SSB). Its chemical composition was determined and this bioprocess was carried out under stationary conditions at $28{ }^{\circ} \mathrm{C}$. The effects of different compounds; copper, iron, Tween 80, ammonium nitrate and manganese, and their variable concentrations on laccase production were investigated in detail. The optimum production of laccase $\left(43,761.33 \pm 3845 \mathrm{U} \mathrm{L}^{-1}\right)$ was achieved on the day of 20 by employing peach waste of $5.0 \mathrm{~g}$ and $70 \mu \mathrm{M}$ $\mathrm{Cu}^{2+}, 18 \mu \mathrm{M} \mathrm{Fe}^{2+}, 0.025 \%$ (v/v) Tween $80,4.0 \mathrm{~g} \mathrm{~L}^{-1}$ ammonium nitrate, $750 \mu \mathrm{M} \mathrm{Mn}^{2+}$ as the inducers. The dye decolorization also researched to determine the degrading capability of laccase produced from peach culture under the above-mentioned conditions. Within this scope of the study, methyl orange, tartrazine, reactive red 2 and reactive black dyes were treated with this enzyme. The highest decolorization was performed with methyl orange as $43 \pm 2.8 \%$ after $5 \mathrm{~min}$ of treatment when compared to other dyes. Up to now, this is the first report on the induction of laccase production by $P$. eryngii under SSB using peach waste as the substrate.
\end{abstract}

Raziye Ozturk Urek

raziye.urek@deu.edu.tr

Merve Akpinar

mmerve.akpinar@gmail.com

1 Chemistry Department, Graduate School of Natural and Applied Sciences, Dokuz Eylül University, 35160 Buca-Izmir, Turkey

2 Biochemistry Division, Chemistry Department, Faculty of Science, Dokuz Eylül University, 35160 Buca-Izmir, Turkey
Keywords Decolorization - Laccase · Peach waste · Pleurotus eryngii $\cdot$ Solid state bioprocessing · Inducer

\section{Introduction}

Laccases (E.C. 1.10.3.2) secreted by most of white rot fungi (WRF), are ligninolytic enzymes belonging to the multicopper oxidases containing four copper atoms in the catalytic center (Bertrand et al. 2013). These enzymes are generally extracellular and catalyze the oxidation of several aromatic amines, phenolic compounds, thiols and some inorganic compounds using molecular oxygen as electron acceptor (Madhavi and Lele 2009). With these properties, they have attracted the attention of many researchers; they have potential applications and used in many fields, including the environmental and industrial sectors such as pharmaceutical, nano-biotech, textile, paper and pulp, food, chemistry, cosmetic due to their low substrate specificities and high redox potentials (Madhavi and Lele 2009; Upadhyay et al. 2016). Moreover, several dyes are commonly use as a colorant in these textile, food, pharmaceutical, paper printing, and photographic, cosmetic, and leather industries (Rodriguez-Couto 2009). Reactive dyes are use generally in the dyeing industries due to their effective solubility, superior to color fastness properties to the applied fabric, high photolytic stability, and resistance to microbial deterioration (Spadaro et al. 1992). Their degradations are of great importance in terms of ecological system. One of their degradations was carried out by WRF and their extracellular enzyme systems, especially laccases (Dos Santos et al. 2015). Considering the high volumes of these enzymes used mentioned industries, the cost of laccases productions is one of the main factors determining

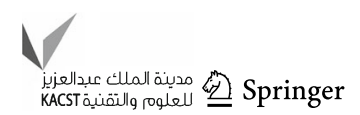


the economy of the process. Solid state bioprocessing (SSB) may solve these problems. SSB is defined as a fermentation process in which the substrate itself acts as carbon/energy source, occurring in the absence or nearabsence of free water (Pandey et al. 2000). Compared with submerged fermentation, SSB can obtain higher product titers with low energy consumption, low volumes and low equipment costs, and most notably without effluents and less pollution (Raimbault 1998). In addition, lignocellulosic materials mainly comprising of cellulose, hemicelluloses and lignin are generally better substrates for enzyme production in SSB (Anwar et al. 2014; El-Bakry et al. 2015). Thus, approaches that are more recent have focused on utilizing agroindustrial wastes, one of lignocellulosic substrates, as a raw material for the production of microbial metabolites for food processing industries (El-Bakry et al. 2015). This has gained increasing ground because agrobased raw materials such as coffee pulp and husk, sugar beet pulp, sugarcane bagasse and bran of pulses have the advantage of using as a sole source of energy and C-pool and are environment friendly. Productions of laccases by WRF have studied as they secrete these enzymes and grow on lignocellulosic substrates (Rodríguez-Couto and Sanromán 2005).

Medium optimization has become one of the main ways to realize the production of enzyme by submerged fermentation/SSB because enzyme production is highly regulated by the media composition or ingredients (Singh and Chen 2008). It is known that the productions of laccases are affected by many fermentation factors such as medium composition, carbon and nitrogen sources and their concentrations, $\mathrm{pH}$, temperature, etc. (Stajic et al. 2006; Patel et al. 2009; Xin and Geng 2011). Furthermore, many compounds have been widely used to stimulate laccases productions via the use of inducers (Patel et al. 2009). Until now, various lignocellulosic residues, e.g., mandarin peels, walnut leaves, wheat bran, banana peels, apricot, pomegranate wastes, etc., have used in laccase production by some WRF under SSB conditions (Elisashvili and Kachlishvili 2009; Akpinar and Ozturk Urek 2014). To the best our knowledge, peach waste from fruit juice industry was not tested as a substrate for laccase production. The objective of this study is to optimize the SSB to get higher laccase production economically by Pleurotus eryngii of WRF grown on peach waste by investigating the effects on different concentrations of copper, iron, Tween 80, ammonium nitrate and manganese. In addition, the decolorization efficiency of four reactive dyes also evaluated with the produced laccase enzyme-highest activity under optimized SSB conditions.

\section{Materials and methods}

\section{Microorganism and culture conditions}

The fungus P. eryngii (DC.) Gillet (MCC58) procured from the culture collection of Agroma Mushroom (Denizli, Turkey). It was sporulated on malt extract pepton agar (MPA) composed of $\left(\mathrm{g} \mathrm{L}^{-1}\right)$ : malt extract, 30.0; peptone 3.0 and agar, $15.0\left(\mathrm{pH} \mathrm{5.6)}\right.$ at $25 \pm 0.5^{\circ} \mathrm{C}$ (Akpinar and Ozturk Urek 2014). The fungal cultures were maintained by periodical subculturing on MPA at $25 \pm 1{ }^{\circ} \mathrm{C}$ and stored at $4 \pm 1{ }^{\circ} \mathrm{C}$.

\section{Solid waste and its chemical compositions}

An agroindustrial peach waste (PW), attained from the Dimes fruit juice factory, Izmir, Turkey, was collected and used as the solid substrate for the SSB. According to knowledge from Dimes fruit juice factory, the peach fruits cultivated in the Aegean region of Turkey harvested at optimum technological maturity. Their PWs came for two or three pressing to make fruit juice. Total carbohydrate, protein, lignin and cellulose contents of this waste were determined (Saha and Brewer 1994; Bradford 1976; Bruce and West 1989; Romero et al. 2010).

\section{Laccase production under solid state bioprocessing}

SSB was carried out in $100 \mathrm{~mL}$ Erlenmeyer flasks, each having $5.0 \mathrm{~g}$ of non-pretreated peach waste moistened with $10 \mathrm{~mL}$ basal medium as a moistening agent $\left(\mathrm{g} \mathrm{L}^{-1}: \mathrm{NH}_{4}\right.$ $\mathrm{NO}_{3}, \quad 2.0 ; \quad \mathrm{KH}_{2} \mathrm{PO}_{4}, \quad 0.8 ; \quad \mathrm{K}_{2} \mathrm{HPO}_{4} \times 7 \mathrm{H}_{2} \mathrm{O}, \quad 0.75 ;$ $\mathrm{MgSO}_{4} \times 7 \mathrm{H}_{2} \mathrm{O}, 0.5$; yeast extract, $2.0 ; \mathrm{ZnSO}_{4} \times 7 \mathrm{H}_{2} \mathrm{O}$, $0.002 ; \quad \mathrm{FeSO}_{4} \times 7 \mathrm{H}_{2} \mathrm{O}, \quad 0.005 ; \quad \mathrm{CaCl}_{2} \times 2 \mathrm{H}_{2} \mathrm{O}, \quad 0.06 ;$ $\mathrm{CuSO}_{4} \times 7 \mathrm{H}_{2} \mathrm{O}, 0.02 ; \mathrm{MnSO}_{4} \times \mathrm{H}_{2} \mathrm{O}, 0.05$ and $\mathrm{pH}$ 6.0) to obtain the solid waste amount-to-moistening agent volume ratio of 1:2 (Stajíc et al. 2006; Akpinar and Ozturk Urek 2014). The $\mathrm{pH}$ of medium was adjusted to 6.0 after sterilization by autoclaving. Thereafter, the flasks were cooled to room temperature and inoculated with three agar plugs $\left(1 \mathrm{~cm}^{2}\right.$ disks) cut from actively growing culture (12 days old). The fermentation was carried out in a controlled environment with temperature at $28.0 \pm 0.5^{\circ} \mathrm{C}$ for 30 days under stationary condition in complete darkness. The fungal fermented PW was removed from each flask, suspended in $50 \mathrm{~mL}$ acetate buffer $(50 \mathrm{mM}, \mathrm{pH} 5.0)$ and shaken for an hour at $180 \mathrm{rpm}$. Solids were separated by centrifugation $\left(4 \pm 1{ }^{\circ} \mathrm{C}, 15,000 \mathrm{rpm}, 10 \mathrm{~min}\right.$ ) (Akpinar and Ozturk Urek 2014), and supernatants were used for measurements of the extracellular laccase enzyme activity, meanwhile, the changes in the protein levels has 
investigated during the incubation period. Experiments were done triplicate and samples were analyzed in triplicate.

\section{Optimization of laccase production}

The laccase production by the $P$. eryngii under SSB was optimized. Firstly, the effect of concentrations of copper $(35-2000 \mu \mathrm{M})$ and iron $(10-1000 \mu \mathrm{M})$ ions using sulfate as the donor was researched. Then, the influence of surfactant, Tween $80,(0.0-0.2 \%, \mathrm{v} / \mathrm{v})$ to enhance laccase production was also investigated. After that, ammonium nitrate $\left(1.0-4.0 \mathrm{~g} \mathrm{~L}^{-1}\right)$ and manganese sulfate $(180-1000 \mu \mathrm{M})$ concentrations were tested. In addition, the basal medium under control condition contained $70 \mu \mathrm{M}$ copper, $18 \mu \mathrm{M}$ iron, $180 \mu \mathrm{M}$ manganese and $2.0 \mathrm{~g} \mathrm{~L}^{-1}$ ammonium nitrate, while no Tween 80 as described in the text.

\section{Analytical methods}

Lac activity was assayed by measuring the oxidation of 2,2-amino-bis (3-ethyl benzothiazoline-6-(sulfonate) according to Johannes and Majcherczyk with minor modifications (Johannes and Majcherczyk 2000). The enzymatic activity of $1 \mathrm{U}$ was defined as the amount of enzyme that transforms $1 \mu \mathrm{mol}$ substrate/min. Protein levels were determined by the methods of Bradford (1976) dye binding.

\section{Dye decolorization}

In vitro dye decolorization studies were analyzed with methyl orange (MO), tartrazine (TT), reactive red 2 (RR) and reactive black $5(\mathrm{RB})$ dyes. The reaction carried out at $25 \pm 1{ }^{\circ} \mathrm{C}$ and with two dye concentrations, 50 and $100 \mathrm{ppm}$, without any mediators. Decolorization was spectrophotometrically determined by monitoring the decrease in absorbancy at the maximum visible absorbancy of each dye (MO at $505 \mathrm{~nm}$, TT at $425 \mathrm{~nm}, \mathrm{RR}$ at $538 \mathrm{~nm}$ and RB at $597 \mathrm{~nm}$ ) (Michniewicz et al. 2008). In parallel, control samples were maintained with heat-inactivated enzyme. The decolorization degree was calculated using the following formula:

$D=100\left(A_{\text {ini }}-A_{\text {obs }}\right) / A_{\text {ini }}$,

where $D$ is the decolorization degree (in percent), $A_{\text {ini }}$ the initial absorbancy, and $A_{\mathrm{obs}}$ the observed absorbancy.

\section{Statistical analysis}

All statistical analyses were performed with the program SPSS 15.0 for Windows. The all values were the mean of three separate experiments.

\section{Results and discussion}

WRF are the most efficient microorganisms for laccases productions in the fermentation of agricultural materials due to their lignocellulosic compositions (Anwar et al. 2014). The synthesis and activity of extracellular laccase are dependent on a number of factors that include the composition of the culture medium such as the nitrogen and/or carbon source and whether the organism is cultured in SSB or fermentation systems (Singh and Chen 2008). In this study, a highly efficient strategy for laccase production with higher activity by $P$. eryngii was developed under SSB using PW without any pretreatments. Many agroindustrial wastes were tested for laccase production, but PW has not been reported in production of laccase enzymes by fungi as per the published literature so far to the best of our knowledge. Namely, this waste was investigated for the first time for the production of laccase by $P$. eryngii and the use of it for SSB as a substrate. PW was used as a nutritional source and enzyme inducer in the SSB because it is rich in important nutrients, including cellulose, lignin, reducing sugar, nitrogen, etc. The chemical compositions of PW involved $18.59 \pm 1.1 \%$ total carbohydrate, $0.08 \pm 0.005 \%$ protein, $40.56 \pm 3.1 \%$ lignin and $4.63 \pm 0.3 \%$ cellulose, so this waste was lignocellulosic. To reduce the cost of laccase production, the use of industrial and agricultural waste or by-products containing laccase inducers such as lignin is an efficient alternative strategy (Elisashvili and Kachlishvili 2009). In addition, PW was directly utilized as carbon and energy source in this study, because any treatment methods may cause rises in production costs and lower laccase activity was observed when the peach waste treated with hot water, dilute acid and base (data not shown).

In this study, five parameters, copper, iron, Tween 80, ammonium nitrate, manganese and their different concentrations were optimized to obtain maximum laccase production from SSB of $P$. eryngii using PW.

\section{Effect of copper concentrations on laccase production by $P$. eryngii}

One of the important factors affecting biodegradation processes is the presence of metals in fungal environment. Heavy metals can be toxic for WRF and affect their growth and the activity of extracellular enzymes. In comparison with heavy metals, little is known what the function of essential metals, such as copper, iron and manganese in lignocellulose degradation (Baldrian 2003). Copper atoms served as cofactors in the catalytic core of laccase; thus, a minimum concentration (millimolar range) of copper ions was necessary for production of the active enzyme 
(Bertrand et al. 2013; Patel et al. 2009). In this study, the effects of copper concentrations on laccase activities have investigated during the stationary cultivation and time dependent. The all tested copper concentrations were 35 , $100,500,1000,2000 \mu \mathrm{M}$, also the copper concentration in control medium was $70 \mu \mathrm{M}$. Figure 1 illustrates the role of increasing copper concentrations in laccase production by $P$. eryngii. The laccase production increased as the concentration of copper increased up to $70 \mu \mathrm{M}$, then decreased. The addition of copper to the culture medium above $70 \mu \mathrm{M}$ resulted in maximum laccase activities inferior to the control. On the other hand, the incubation time obtaining maximum Lac activities was observed in the 15th, 17th, 20th day of incubation in the presence of 35, 70, $100 \mu \mathrm{M} \mathrm{Cu}{ }^{2+}$, respectively, while the Lac activities reached to maximum in the same day of incubation (10th) in supplemented 500, 1000, $2000 \mu \mathrm{M} \mathrm{Cu}^{2+}$. The highest laccase activity was determined as $2193.056 \pm 50.4 \mathrm{U} \mathrm{L}^{-1}$ under control condition. According to our results, conditions promoting laccase expression by $P$. eryngii appeared to be different to those reported by many other fungi. Especially, higher laccase activity was indicated with increasing copper concentrations in the medium to other reports (Patel et al. 2009; Piscitelli et al. 2011), whereas our findings in this research demonstrate that the rising copper concentrations did not affect laccase activity positively. Copper concentrations above $70 \mu \mathrm{M}$ could showed the toxic effect on laccase productions, and thus reduce the activity. Xin and Geng (2011) found that the supplementation of copper $(1 \mathrm{mM})$ to the defined basal medium induced laccase production by Trametes versicolor under SSB conditions. Different studies have shown that laccase activity has regulated by copper ions through gene expression induction or translational or post- translational regulation (Fonseca et al. 2010). On the other hand, Elsayed et al. (2012) supported our results. They reported that among the tested copper concentrations (50, $100,250,500,750,1000,1250$, and $1500 \mu \mathrm{M}), 100 \mu \mathrm{M}$ supported the maximum laccase production by $P$. ostreatus ARC280 compared to the original medium containing $50 \mu \mathrm{M} \mathrm{Cu}^{2+}$, and significant decrease in laccase activity was observed when the concentration of copper was increased beyond $100 \mu \mathrm{M}$.

\section{Effect of iron concentrations on laccase production by $P$. eryngii}

Since $\mathrm{Fe}^{2+}$ has been reported to regulate the expression of fungal laccases at the transcription level, different concentrations of $\mathrm{FeSO}_{4}(10,18,25,40,100,500,1000 \mu \mathrm{M})$ were tested in terms of laccase release. The addition of this salt to the basal medium up to including $18 \mu \mathrm{M} \mathrm{Fe} \mathrm{Fe}^{2+}$ enhanced the production of laccase by $P$. eryngii of peach cultures. Figure 2 shows that laccase secretion was negligible $\left(<2.0 \mathrm{U} \mathrm{L}^{-1}\right)$ in the early days of incubation on control cultures, and that iron supplementation, especially at low concentrations, resulted in a marked increase in laccase activity. $\mathrm{FeSO}_{4}$ at $18 \mu \mathrm{M}$ resulted in a maximum laccase activity of $2193.056 \pm 50.4 \mathrm{U} \mathrm{L}^{-1}$ on the day of 17. The optimal iron concentration for laccase synthesis by $P$. eryngii under SSB cultures using PW has found to be $18 \mu \mathrm{M}$ in the presence of $70 \mu \mathrm{M} \mathrm{Cu}^{2+}$. The iron concentrations above $18 \mu \mathrm{M}$ negatively affected laccase activity. Many researches showed that the laccase production by the iron regulated at transcriptional level (Zhu and Williamson 2003). However, the supplementation of iron found to be less effective to induce the laccase activity according to our results. In other words, $18 \mu \mathrm{M}$ of iron concentration was
Fig. 1 The influence of copper concentrations on laccase production throughout incubation time. The values are the mean $\pm \mathrm{SD}$ for experiments of three separate experiments

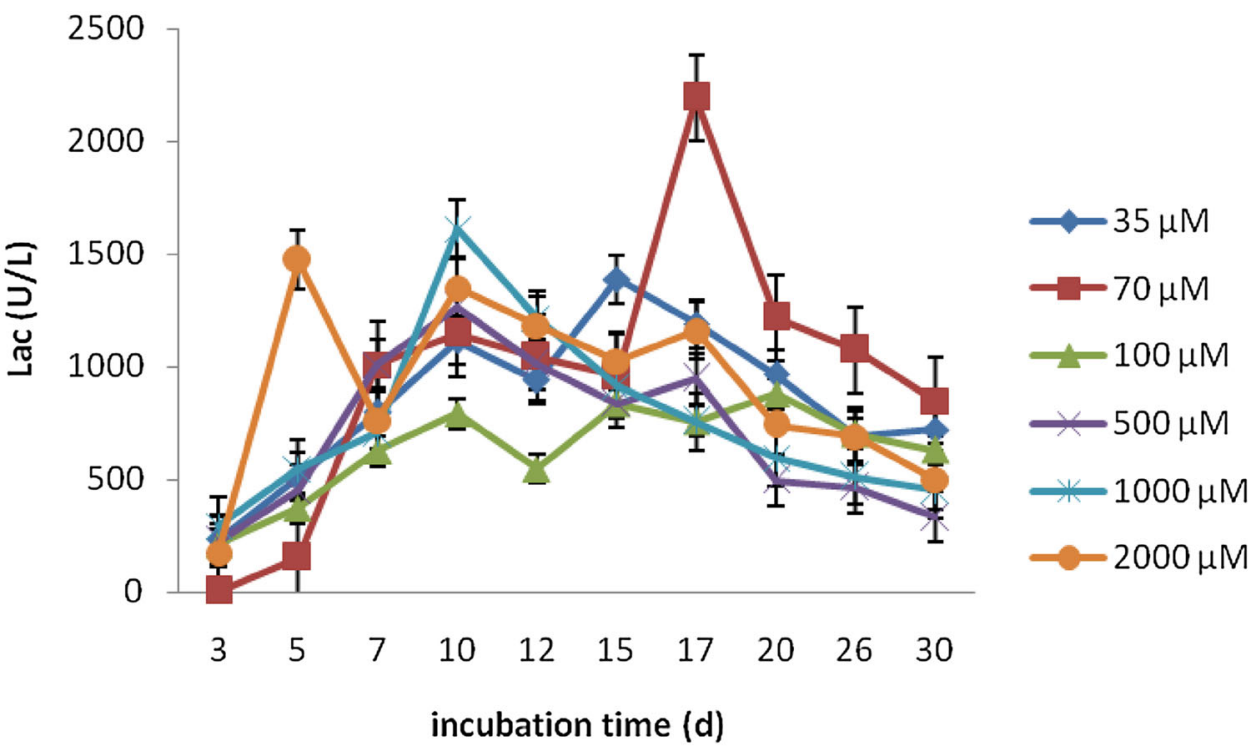


Fig. 2 The influence of iron concentrations on laccase production throughout the mean $\pm \mathrm{SD}$ for experiments of three separate experiments incubation time. The values are

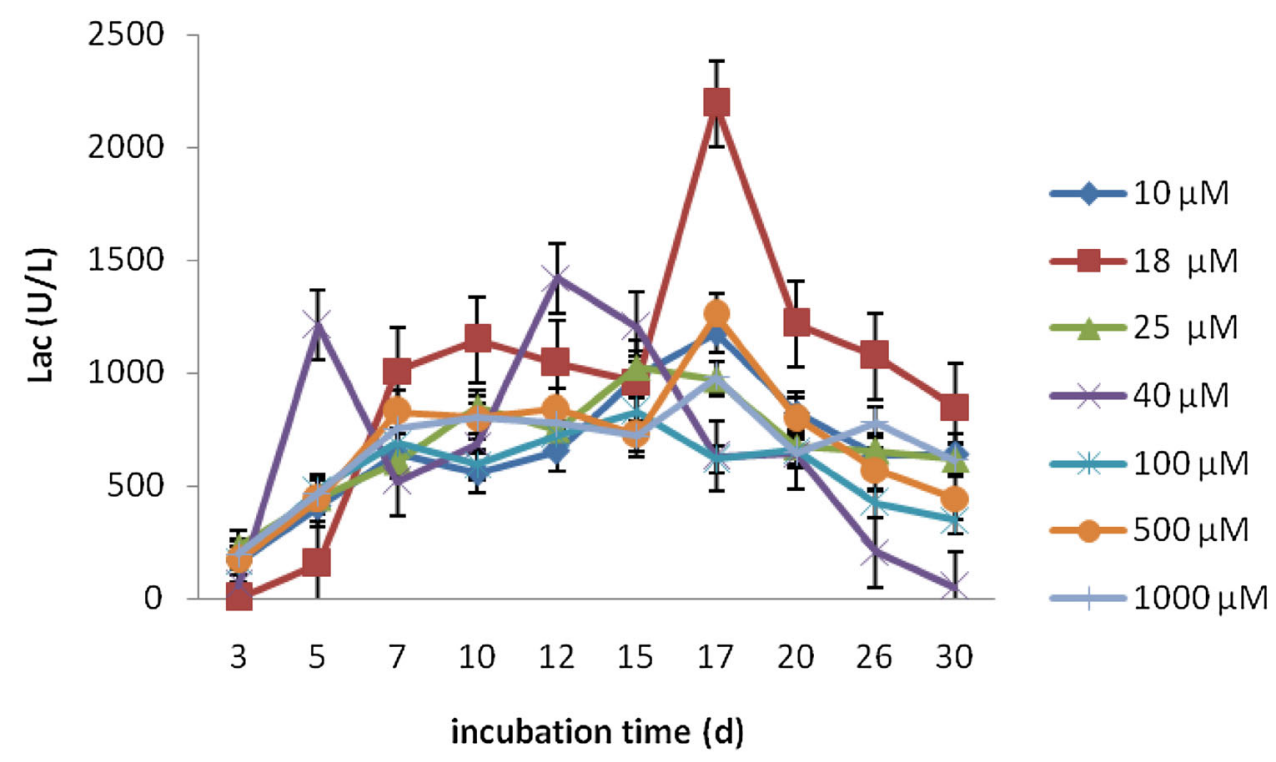

Fig. 3 The influence of Tween 80 concentrations on laccase production throughout incubation time. The values are the mean $\pm \mathrm{SD}$ for experiments of three separate experiments

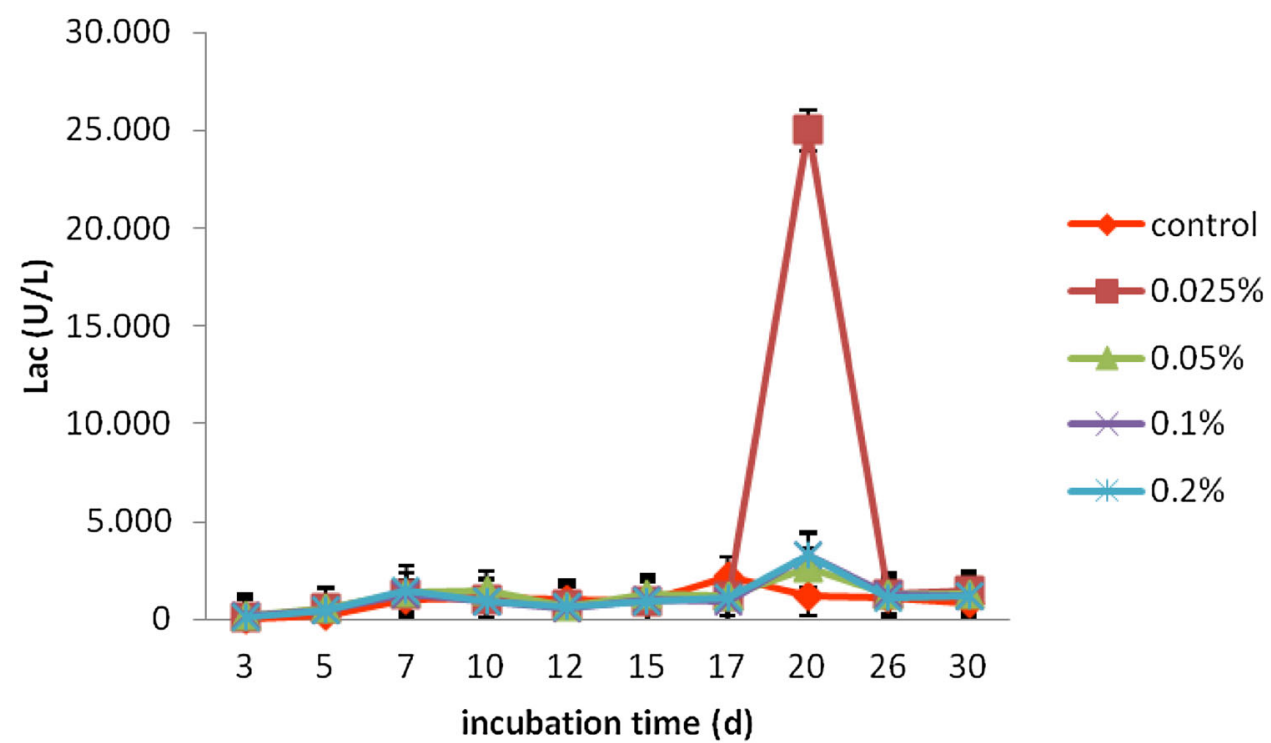

enough for laccase production and synthesis by $P$. eryngii under SSB conditions at the transcriptional level. It can originate from that ions such as iron may interrupt the electron transport system of laccase and substrate conversion (Kim and Nicell 2006).

\section{Effect of Tween 80 concentrations on laccase production by $P$. eryngii}

The effect of surfactant supplementation, Tween 80 , to the defined basal medium was investigated. According to our preliminary studies, this compound was added to basal medium with the concentration of $0.05 \%$, v/v. Since the laccase activity was stimulated by this (data not shown), various concentrations were incorporated in the fermentation medium at the time of inoculums transfer as can be seen in Fig. 3 to study the effect of Tween 80 on laccase activities. The Tween 80, non-ionic detergent, influenced the laccase activities in all culture conditions supplemented with different concentrations $(0.025,0.05$, $0.1,0.2 \%, \mathrm{v} / \mathrm{v})$. The maximal laccase activities in all Tween 80-supplemented conditions were attained on the 20 days of incubation, but it was on 17th day under control conditions. The maximum laccase activity was observed as $24,987.565 \pm 2145 \mathrm{U} \mathrm{L}^{-1}$ in the presence of $0.025 \%, \mathrm{v} / \mathrm{v}$, Tween 80 , and this value was 11.4 -fold higher than that obtained in the control culture $(p<0.01)$. Thus, these results clearly show the positive effect of Tween 80 as an inducer of laccase activity. Surfactants such as Tween 80 that modify the fungal membrane are known to be 
promoting laccase secretion by many fungal strains (Dekker et al. 2007). Elsayed et al. (2012) studied the effect of different concentration of Tween $80(0.1-0.75 \%$; v/v) on laccase activity, and they found that the enzyme activity reached to its maximum value at a concentration of $0.1 \%$ (v/v Tween-80) and increased by about $44 \%$ than control (without Tween-80). The increase in laccase activity in the presence of Tween 80 might be due to increased permeability of the cell membrane's lipid bilayer, facilitating more rapid secretion of enzymes out of the cell. On the other hand, this surfactant could protect the enzyme structure and its activity from environmental factors forming micelles around the enzyme. Moreover, the solubility of compounds in lignocellulosic structure may be increased, and thus better surface area may provide for the utilization of the fungus in the presence of Tween 80 .

\section{Effect of ammonium nitrate concentrations on laccase production by $P$. eryngii}

As it can be observed in Fig. 4, the joint effect of ammonium nitrate concentrations $\left(1.0,2.0,4.0 \mathrm{~g} \mathrm{~L}^{-1}\right)$ on laccase activities by $P$. eyngii was studied under SSB containing $70 \mu \mathrm{M} \mathrm{Cu}^{2+}, 18 \mu \mathrm{M} \mathrm{Fe}^{2+}$ and $0.025 \%$, v/v, Tween 80 . This effect was very significant and the maximum laccase activity was obtained by culture supplemented with $4.0 \mathrm{~g} \mathrm{~L}^{-1}$ ammonium nitrate, recorded as $28,124.982 \pm 2345 \mathrm{U} \mathrm{L}^{-1}$ on the 20 day of incubation. This maximum value was 12.82 -fold higher than that obtained in the control culture $(p<0.01)$. So, this effect was considered in the subsequent experiments. There were many studies proving the stimulatory effect of both the nature and concentration of nitrogen sources on laccase activity (Patel et al. 2009). In secondary metabolic pathways such as laccase production, nutritional requirements have been differed depending on culture conditions and fungal strains. Some of them produced the high activity of laccase enzyme under nitrogen-limited conditions or vice versa (Mikiashvili et al. 2006). The reason of obtaining a higher laccase activity might be better regulated the synthesis the enzyme in the presence of higher concentrations of ammonium nitrate when compared to control condition.

\section{Effect of manganese concentrations on laccase production by $P$. eryngii}

As depicted in Fig. 5a, the Lac activity by $P$. eryngii ranged from $136.764 \pm 9.2$ to $43761.33 \pm 3845 \mathrm{U} \mathrm{L}^{-1}$ for all researched manganese concentrations $(180,250,500$, $750,1000 \mu \mathrm{M})$. The highest activity value of this enzyme was determined as $43761.33 \pm 3845 \mathrm{U} \mathrm{L}^{-1}$ on the 20th day of incubation. This value under optimized conditions $\left(70 \mu \mathrm{M} \mathrm{Cu}^{2+}, 18 \mu \mathrm{M} \mathrm{Fe}^{2+}, 0.025 \%\right.$, v/v, Tween 80, $4.0 \mathrm{~g} \mathrm{~L}^{-1}$ ammonium nitrate, $750 \mu \mathrm{M} \mathrm{Mn}^{2+}$ ) was 19.95fold greater than that of control's $(p<0.01)$. Therefore, laccase production was enhanced under such condition. In our experiments, manganese concentration, $750 \mu \mathrm{M}$, was optimal for laccase production. Vantamuri and Kaliwal (2016) stated that rice bran was the best substrate for production under SSF conditions when compared to other lignocellulosic substrates, rice straw, sugarcane bagasse, saw dust, pigeon pea waste. The maximum laccase in that study was approximately recorded as $1.4 \mathrm{U} \mathrm{mL}^{-1}$ and this value was 31.29 -fold lower than that of the highest laccase activity obtained in this study. In addition, the laccase activity before the optimization of SSB using peach waste was also higher than their values. In another study, the effect of the utilization of wheat straw and oak sawdust by Ganoderma applanatum BEOFB 411 on laccase activity was researched by Ćilerdžić et al. (2016). Wheat straw was
Fig. 4 The influence of ammonium nitrate concentrations on laccase production throughout incubation time. The values are the mean $\pm \mathrm{SD}$ for experiments of three separate experiments

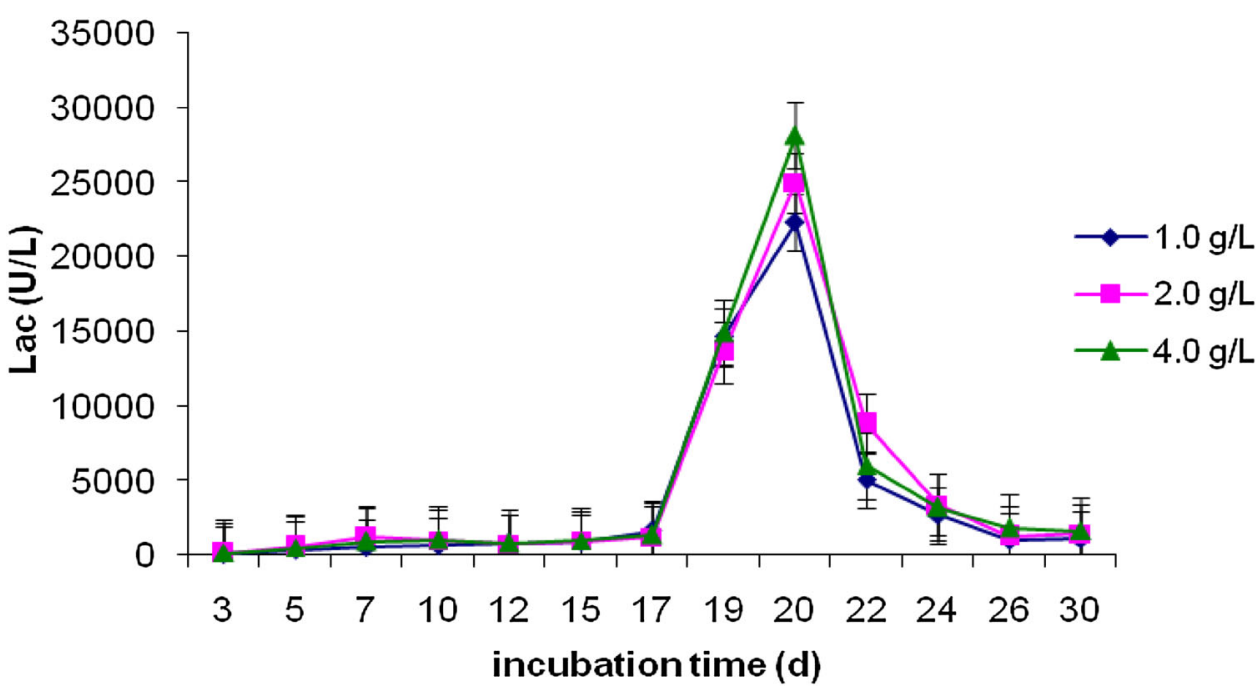


Fig. 5 a The influence of manganese concentrations on laccase production throughout incubation time. The values are the mean \pm SD for experiments of three separate experiments. b The influence of increasing manganese concentrations on the protein and highest laccase productions. The values are the mean \pm SD for experiments of three separate experiments
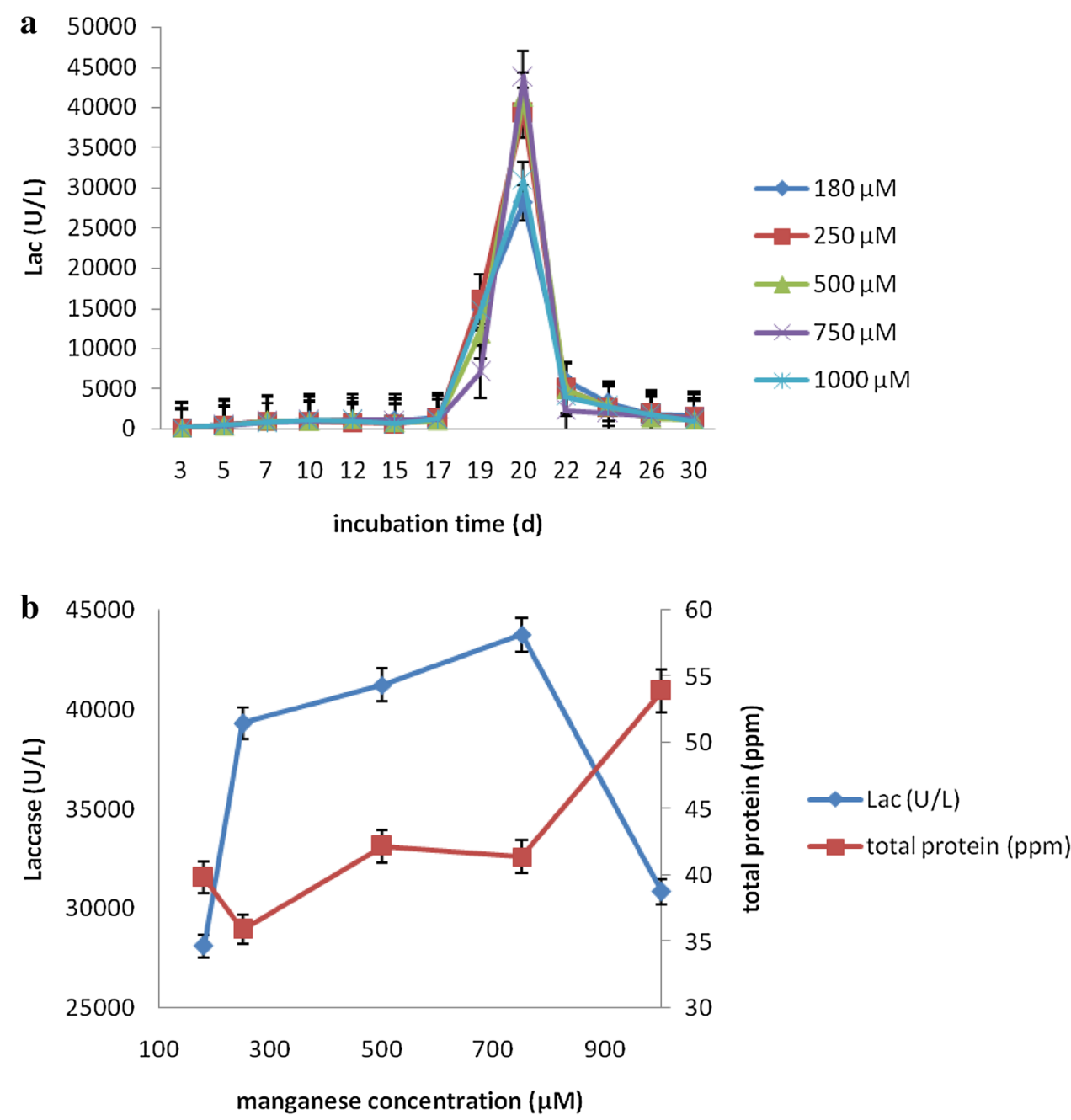

better substrate for laccase activity under SSF conditions, and it was approximately detected as $3000 \mathrm{U} \mathrm{L}^{-1}$.

Figure $5 \mathrm{~b}$ demonstrated the protein and maximum laccase productions of 20-day peach cultures. The laccase production by $P$. eryngii was gradually increased up to 750 $\mu \mathrm{M}$ manganese concentration, and then it decreased at upper manganese concentration. In addition, the protein productions remained with the increasing manganese concentration except $250 \mu \mathrm{M}$ similar to laccase productions and higher manganese concentrations favored the soluble protein production. The maximal protein concentration was $53.906 \pm 3.9 \mathrm{ppm}$ in $1000 \mu \mathrm{M}$ manganese and this result was approximately 1.3 -fold higher than that obtained in $750 \mu \mathrm{M}(p<0.05)$. Contrary to the $\mathrm{Cu}^{2+}$ and $\mathrm{Fe}^{2+}$, the $\mathrm{Mn}^{2+}$ showed stimulatory effect on laccase activity in $P$. eryngii under SSB. According to literature, manganese was also effective inducer of laccase in many WRF (Piscitelli et al. 2011). Positive impact of some $\mathrm{Mn}^{2+}$ concentrations on laccase activity, Piscitelli et al. (2011) may be explained by the induction of gene transcription. The specific activity of laccase under optimized conditions was calculated as
$1050.28 \pm 86 \mathrm{U} \mathrm{mg}^{-1}$. Imran et al. (2016) found that the maximum specific activity of laccase synthesized by Aspergillus terreus SG-777 was determined as $0.91 \mathrm{U} \mathrm{mg}^{-1}$ using banana stalks as a substrate after improving SSF conditions, and it was approximately 1154-fold lower than our result. In the another study, under solid state fermentation, the maximum laccase specific activities obtained were 26.25 and $12.13 \mathrm{U} \mathrm{mg}^{-1}$ on 4 and $40 \mathrm{ppm}$ lindane incorporated samples, respectively, on the 28th day of incubation (Kaur et al. 2016). Similarly, these values were too low than those of $1050.28 \pm 86 \mathrm{U} \mathrm{mg}^{-1}$; thus, these results may be evidence of the efficiency of SSF.

\section{In vitro dye decolorization}

Synthetic dyes such as MO, TT, RR and RB were treated with produced laccase enzyme with highest activity obtained from optimized peach cultures after 20 days without the addition redox or laccase mediators. As can be seen in Fig. 6, the highest decolorization was performed 
Fig. 6 The decolorization of some azo dyes with highest laccase activity obtained from peach culture. The values are the mean \pm SD for experiments of three separate experiments

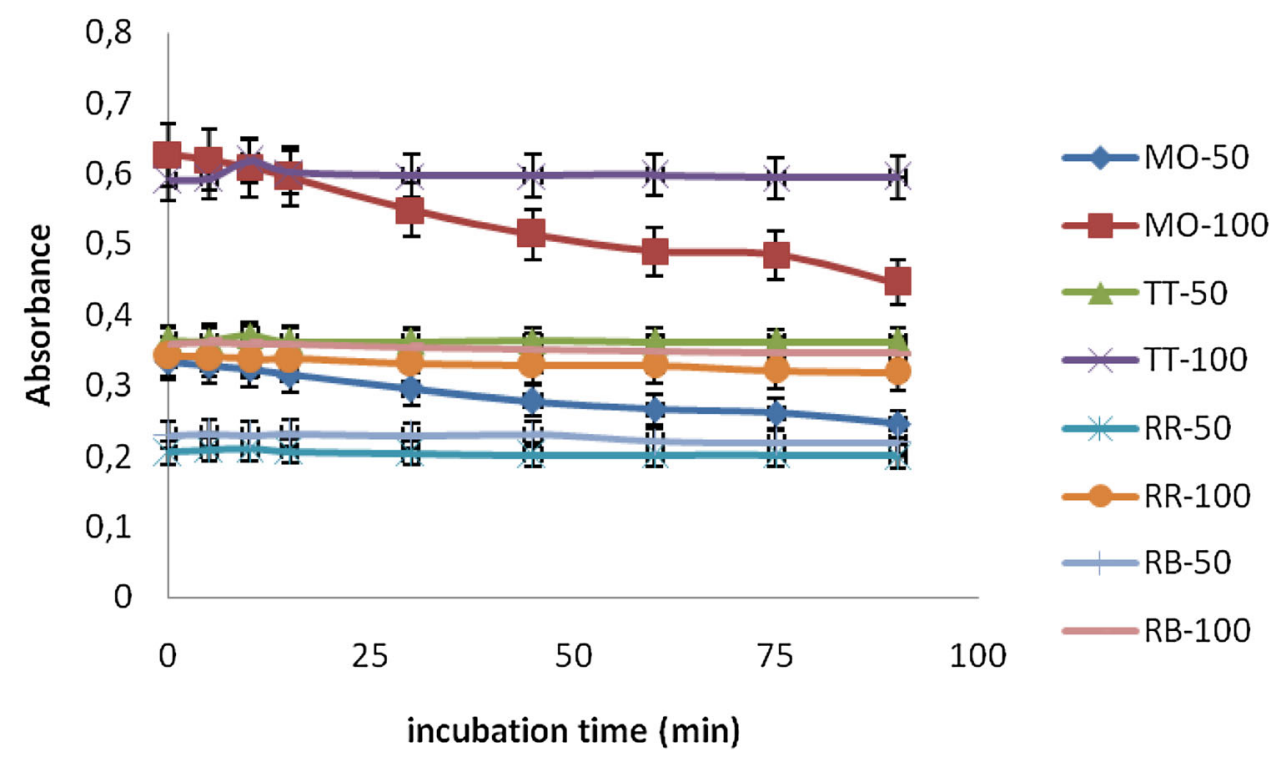

with MO $\left(50 \mathrm{mg} \mathrm{L}^{-1}\right)$ as $43 \pm 2.8 \%$ after $5 \mathrm{~min}$ of treatment by the laccase enzyme obtained from peach culture. This is an extremely short period to achieve azo dye decolorization. The decolorizations of these azo dyes with the improved Lac enzyme of $P$. eryngii show its potential as a source of industrial enzymes for biotechnological applications. Xin and Geng (2011) researched the laccase production by $T$. versicolor under SSF conditions and the decolorization performance of this enzyme. According to their results, indigo carmine and bromophenol dyes were completely decolorized in $24 \mathrm{~h}$, while phenol red was $36 \%$ at $24 \mathrm{~h}$.

Knežević et al. (2013) studied the seven fungal species' abilities for lignin degradation of wheat straw via laccase and other ligninolytic enzymes (Knežević et al. 2013). They found that Pleurotus ostreatus HAI 595 and $P$. eryngii HAI 507 were distinguished from the other species by significantly higher laccase activities reaching maxima of 4808.7 and $4531.0 \mathrm{U} \mathrm{L}^{-1}$, and these maximum values were 9.1- and 9.66-fold lower than that of our highest activity value of laccase enzyme. In another study, Zilly et al. (2012) researched the SSB of passion fruit waste by white rot fungi $P$. ostreatus, Pleurotus pulmonarius, Macrocybe titans, Ganoderma lucidum, and Grifola frondosa for production of oxidative and hydrolytic enzymes. Yellow passion fruit waste was as good as substrate as peach waste due to rich in carbohydrate. The laccase activities ranged from 6040 to $10,200 \mathrm{U} \mathrm{L}^{-1}$ in all cultures when the yellow passion fruit waste used as substrate by fungi. Banana peel was the best substrate among the other tested lignocellulosic agro-residues, poplar leaves, wheat bran, rice bran, wheat straw, and bagasse under SSB conditions for obtaining higher laccase production. The laccase activity reached to maximum as $6281.4 \mathrm{U} \mathrm{L}^{-1}$ under optimized conditions of banana peel culture (Vivekanand et al. 2011). Our highest laccase activity was 6.97-fold higher than that of it. In our previous work, the maximum laccase activities were detected as 1618.5 and $373.5 \mathrm{U} \mathrm{L}^{-1}$ using apricot and pomegranate wastes from fruit juice industry by $P$. eryngii under SSB conditions, respectively (Akpinar and Ozturk Urek 2014). The bioprocess optimization was of great importance for getting higher laccase activity. Therefore, Risdianto et al. (2010) investigated the influence of temperature on laccase production in SSB by using white rot fungus Marasmius sp. using rice straw as the solid support material. The highest laccase activity was achieved as $1564.17 \mathrm{U} \mathrm{L}^{-1}$ in their study under derived conditions. Many nutritional parameters in our study were researched together for attaining higher laccase production under SSB conditions when considering the available literature. In addition, there were many studies for laccase production using agro-industrial wastes from many sectors. Peach waste, one of them, was assimilated by $P$. eryngii due to its chemical composition; thus, the bioconversion of it was carried out though biological treatment, which is one way of environmental protection.

\section{Conclusion}

This is the first report on the optimization of laccase production by $P$. eryngii using peach waste as the substrate under SSB conditions. Laccase production at high activity was performed; thus, the biotransformation of the product with biotechnological importance was economically occurred via the utilization of peach waste. By far, one of the most effective approaches to increase the yield of laccase enzyme is the supplementation of the nutrient 
medium with appropriate inducers, Tween 80 , ammonium sulfate and manganese. Future studies will focus towards purifying the enzyme as well as testing it in industrial and environmental biotechnology.

Acknowledgements We are thankful to Scientific Research Project of Dokuz Eylül University for financial supports (Project No. 2012.KB.FEN.078). We also are thankful to Dimes, Izmir for providing biomass for research

\section{Compliance with ethical standards}

Conflict of interest The authors declare that they have no competing interests.

\section{References}

Akpinar M, Ozturk Urek R (2014) Extracellular ligninolytic enzymes production by Pleurotus eryngii on agroindustrial wastes. Prep Biochem Biotech 44:772-781

Anwar Z, Gulfraz M, Irshad M (2014) Agro-industrial lignocellulosic biomass a key to unlock the future bio-energy: a brief review. J Radiat Res Appl Sci 7:163-173

Baldrian P (2003) Interactions of heavy metals with white-rot fungi. Enzyme Microb Technol 32:78-91

Bertrand B, Martínez-Morales F, Trejo-Hernandez MR (2013) Fungal laccases: induction and production. Rev Mex Ing Quim $12: 473-488$

Bradford M (1976) A rapid and sensitive method for the quantitation of microgram quantities of protein utilizing the principle of protein-dye binding. Anal Biochem 72:248-254

Bruce RJ, West CA (1989) Elicitation of lignin biosynthesis and isoperoxidase activity by pectic fragments in suspension cultures of castor bean. Plant Physiol 9:889-897

Ćilerdžić J, Stajić M, Vukojević J (2016) Degradation of wheat straw and oak sawdust by Ganoderma applanatum. Int Biodeter Biodegr 114:39-44

Dekker RFH, Barbosa AM, Giese EC, Godoy SDS, Covizzi LG (2007) Influence of nutrients on enhancing laccase production by Botryosphaeria rhodina MAMB-05. Int Microbiol 10:177-185

Dos Santos YVS, Freire DA, Pinheiro S, Fontão L, de Souza JVB, Cavallazzi JRP (2015) Production of laccase from a white rot fungi isolated from the Amazon forest for oxidation of Remazol Brilliant Blue-R. Sci Res Essays 10:132-136

El-Bakry M, Abraham J, Cerda A, Barrena R, Ponsá S, Gea T, Sánchez A (2015) From wastes to high value added products: novel aspects of SSF in the production of enzymes. Crit Rev Env Sci Technol 45:1999-2042

Elisashvili V, Kachlishvili E (2009) Physiological regulation of laccase and manganese peroxidase production by white-rot basidiomycetes. J Biotechnol 144:37-42

Elsayed MA, Mohamed MH, Ali M, Elshafei Bakry MH, Abdelmageed MO (2012) Optimization of cultural and nutritional parameters for the production of laccase by Pleurotus ostreatus ARC280. Br Biotechnol J 2:115-132

Fonseca MI, Shimizu E, Zapata PD, Villalba LL (2010) Copper inducing effect on laccase production of white rot fungi native from Misiones (Argentina). Enzyme Microb Technol 46:534-539

Imran SG, Aziz GM, Razuqi NS (2016) Optimization of ligninolytic enzymes production from Aspergillus terreus SG-777 by solid state fermentation. Iraqi J Vet Med 40(1):116-124
Johannes C, Majcherczyk A (2000) Laccase activity tests and laccase inhibitors. J Biotechnol 78:193-199

Kaur H, Kapoor S, Kaur G (2016) Application of ligninolytic potentials of a white-rot fungus Ganoderma lucidum for degradation of lindane. Environ Monit Assess 188:588-589

Kim Y, Nicell JA (2006) Impact of reaction conditions on the laccase catalyzed conversion of bisphenol A. Bioresour Technol 97:1431-1442

Knežević A, Milovanović I, Stajić M, Lončar N, Brčeski I, Vukojević J, Ćilerdžić J (2013) Lignin degradation by selected fungal species. Bioresour Technol 138:117-123

Madhavi V, Lele SS (2009) Laccase: properties and applications. Bioresources 4:1694-1717

Michniewicz A, Ledakowicz S, Ullrich R, Hofrichter M (2008) Kinetics of the enzymatic decolorization of textile dyes by laccase from Cerrena unicolor. Dyes Pigm 77:295-302

Mikiashvili N, Wasser SP, Nevo E, Elisashvili V (2006) Effects of carbon and nitrogen sources on Pleurotus ostreatus ligninolytic enzyme activity. World J Microbiol Biotechnol 22:999-1002

Pandey A, Soccol CR, Mitchell D (2000) New developments in solid state fermentation: I-bioprocesses and products. Process Biochem 35:1153-1169

Patel H, Gupte A, Gupte S (2009) Effect of different culture conditions and inducers on production of laccase by a basidiomycete fungal isolates Pleurotus ostreatus HP-1 under solid state fermentation. Bioresources 4:268-284

Piscitelli A, Giardina P, Lettera V, Pezzella C, Sannia G, Faraco V (2011) Induction and transcriptional regulation of laccases in fungi. Curr Genomics 12:104-112

Raimbault M (1998) General and microbiological aspects of solid substrate fermentation. Electron J Biotechnol 1:174-188

Risdiantoa H, Suhardib SH, Setiadia T, Kokuganc T (2010) The influence of temperature on laccase production in solid state fermentation by using white rot fungus Marasmius sp. In: The 1st International Seminar on Fundamental and Application of Chemical Engineering (ISFAChE). Bali, pp A009.1-A009.6

Rodríguez-Couto S (2009) Dye removal by immobilized fungi. Biotech Adv 27:227-235

Rodríguez-Couto M, Sanromán A (2005) Application of solid-state fermentation to ligninolytic enzyme production. Biochem Eng $\mathrm{J}$ 22:211-219

Romero I, Ruiz E, Castro E, Moya M (2010) Acid hydrolysis of olive tree biomass. Chem Eng Res Des 88:633-640

Saha SK, Brewer CF (1994) Determination of the concentrations of oligosaccharides, complex type carbohydrates, and glycoproteins using the phenol-sulfuric acid method. Carbohydr Res 254:157-167

Singh D, Chen S (2008) The white-rot fungus Phanerochaete chrysosporium: conditions for the production of lignin-degrading enzymes. Appl Microbiol Biotechnol 81:399-417

Spadaro JT, Gold MH, Renganathan V (1992) Degradation of azo dyes by the lignin-degrading fungus Phanerochaete chrysosporium. Appl Environ Microbiol 58:2397-2401

Stajić M, Persky L, Friesem D, Hadar Y, Wasser SP, Nevo E, Vukojević J (2006) Effect of different carbon and nitrogen sources on laccase and peroxidases production by selected Pleurotus species. Enzyme Microb Technol 38:65-73

Upadhyay P, Shrivastava R, Agrawal PK (2016) Bioprospecting and biotechnological applications of fungal laccase. 3. Biotech 6:189-199

Vantamuri AB, Kaliwal BB (2016) Production of laccase by newly isolated Marasmius sp. BBKAV79 in solid state fermentation and its antiproliferative activity. IJPSR 7(12):4978-4987

Vivekanand V, Dwivedi P, Pareek N, Singh RP (2011) Banana peel: a potential substrate for laccase production by Aspergillus 
fumigatus vkj2.4.5 in solid-state fermentation. Appl Biochem Biotechnol 165:204-220

Xin FX, Geng AL (2011) Utilization of horticultural waste for laccase production by Trametes versicolor under solid-state fermentation. Appl Biochem Biotechnol 163:235-246

Zhu X, Williamson PR (2003) A CLC-type chloride channel gene is required for laccase activity and virulence in Cryptococcus neoformans. Mol Microbiol 50:1271-1281
Zilly A, dos Santos Bazanella GS, Helm CV, Araújo CAV, de Souza CGM, Bracht A, Peralta RM (2012) Solid-state bioconversion of passion fruit waste by white-rot fungi for production of oxidative and hydrolytic enzymes. Food Bioprocess Technol 5:1573-1580 